\title{
A PROPÓSITO DE UNA VENTA DE CUADROS: EXPOLIO Y COLECCIONISMO EN JEREZ DE LA FRONTERA
}

\author{
JOSÉ RAMÓN BARROS CANEDA | UNIVERSIDAD DE CÁDIZ
}

ORCID iD: 0000-0003-4942-6187

\begin{abstract}
RESUMEN
En ocasiones, las fuentes documentales localizadas suministran al historiador sospechas e indicios cuya interpretación y contextualización contribuyen a desvelar los cimientos de los procesos históricos. Bajo esta luz se analizará un interesante e inédito documento que, sin dejar de ser una escueta venta de cuadros, contribuye a perfilar la conducta del modelo de coleccionista burgués de arte, alimentado en España al amparo del proceso desamortizador de 1835.
\end{abstract}

PALABRAS CLAVE

Coleccionismo de arte, Mercado de arte, Jerez de la Frontera, Expolio, Cartuja de Jerez.

Occasionally, the documentary sources found provide the historian with suspicions and clues whose interpretation and contextualisation help to reveal the foundations of historical processes. In this way, we will analyse an interesting and unpublished document which, although it is a brief sale of paintings, helps to outline the behaviour of the model of the bourgeois art collector developed in Spain during the disentailment process of 1835.

\section{KEYWORDS}

Art collecting, Art market, Jerez de la Frontera, Plundering, Carthussian of Jerez. 
a historiografía reciente ha generado abundante literatura sobre coleccionismo y comercio de objetos artísticos y antigüedades en períodos especialmente proclives al estímulo, legal o ilegal, de esa actividad. El progresivo cerco a los componentes y estructuras sociales que articularon esos procesos, ha permitido ir adquiriendo una visión poliédrica sobre los valores que el deslizamiento histórico añade a los bienes artísticos. En este sentido, son fundamentales los estudios realizados sobre el comercio internacional de arte y sus agentes durante los siglos XIX y primer tercio del XX. Estas investigaciones continúan haciendo visibles a comerciantes, marchantes, intelectuales, jerarquías religiosas, así como a las redes de contactos entre vendedores y compradores generadas al amparo de la ineficaz legislación protectora de los bienes históricos y artísticos. Idéntico interés tienen los trabajos sobre mercado legal de arte y tráfico de antigüedades, así como los que se ocupan de analizar y objetivar la actuación de los participantes acusados en determinados momentos de socavar y expoliar los bienes de la nación ${ }^{\text {? }}$.

\section{UNA VENTA DE CUADROS}

Son diversos los autores y autoras que han tratado el discurrir histórico de la Cartuja de $\mathrm{N}^{\mathrm{a}}$. Sra. de la Defensión de Jerez de la Frontera ${ }^{2}$. Del mismo modo, la historiografía tradicional y la más reciente ha ido revelando datos concretos sobre la desaparición/expolio/venta de bienes asociados a la orden cartuja asentada en Jerez desde el siglo XV, contribuyendo a reconstruir un relato esencial para entender la dificultosa consolidación histórica del concepto Patrimonio Cultural en el país.

1 Son fundamentales los trabajos recogidos en ANTIGÜEDAD, María Dolores, ALZAGA RUIZ, Amaya (coord.). Colecciones, expolio, museos y mercado artística en España en los siglos XVIII Y XIX. Madrid: Centro de Estudios Ramón Areces, 2011. PEREZ MULET, Fernando, SOCIAS BATET, Inmaculada (eds.). La dispersión de objetos de arte fuera de España en los Siglo XIX $\gamma$ XX. Barcelona: Universitat de Barcelona y Universidad de Cádiz, 2011. SOCIAS BATET, Inmaculada, GKOZGKOU, Dimitra (eds.). Nuevas contribuciones en torno al mundo del coleccionismo de arte hispánico en los siglos XIX $\gamma$ XX. Asturias: Ediciones Trea S.l., 2013. Del mismo modo, para la comparativa de tasaciones y precios en distintas épocas los artículos de CARRASCO GONZÁLEZ, Guadalupe. La colección de pintura reunida por el comerciante estadounidense Richard Worsan Meade en Cádiz entre 1804 y 1820. Archivo Español de Arte, 2019, 365, pp. 65-82. ISSN 0004-0428 (disponible en http://archivoespañoldearte.revistas.csic.es/index.php/aea/article/view/1057). CARRASCO GONZÁLEZ, Guadalupe. El mercado de la pintura español en Estados Unidos en las primeras décadas de siglo XIX. Quintana: revista de estudios do Departamente de Historia da Arte, 2019, 18, pp. 167-180. DOI: https://doi.org/10.3989/aearte.2019.06 . Del mismo modo REYERO, Carlos. El valor del precio. Tasación y compraventa de pinturas en el Madrid Isabelino (1850-1868). e-artDocuments: revista sobre col-leccions i col-leccioniste. [en línea]. 2009, 1, Seminari: Comerc, Exportació, Falsificació d'objectes d'art. ISSN e 2013-6277. Disponible en https://www.raco.cat/index.php/e-art/article/view/189042/254270. PEREZ VIEJO, Tomas. Géneros, mercado, artistas y críticos en la pintura española del XIX. Espacio, tiempo $\gamma$ Forma. Serie V, Historia Contemporánea, 24, 2012, pp.25.48. Disponible en https:/dialnet.unirioja.es/servlet/ articulo?codigo=4121187. TENA RAMÍREZ, Carmen de. El comercio de Antigüedades en España a comienzos del siglo XX. El caso de José Gestoso y Pérez (1825-1917). Espacio, Tiempo y Forma. Serie VII-Historia del Arte (N. Época), 6, 2018, PP. 349-366. Doi: http://dx.doi.org/10.5944/etfvii.2018.21863

2 Véase, CIRICI NARVÁEZ, Juan Ramón. Juan de la Vega y la arquitectura gaditana del siglo XIX. Cádiz: Colegio Oficial de Arquitectos de Andalucía Occidental, 1992. LOPEZ CAMPUZANO, Julio. La Cartuja de Jerez. Madrid: Julia López Campuzano, 1998. ARENILLAS TORREJÓN, Juan; AROCA VICENTI, Fernando; BARROS CANEDA, José R.; MARTÍNEZ MONTIEL, Luis F. Intramuros. La Cartuja de Nuestra Señora de la Defensión. Jerez: Publicaciones de Sur S.A., 2003. 
En esta línea, es objetivo de este artículo analizar una venta de cuadros interpretada como sospechoso antecedente de una denuncia realizada en 1852 sobre el robo de once lienzos del monasterio jerezano y que dio lugar a un, igualmente interesante, procedimiento judicial en el que estuvo implicado, entre otros, Antonio Jiménez, un médico de Jerez. ${ }^{3}$

Un año antes de la citada denuncia, en 1851, se protocoliza en El Puerto de Santa María una venta de cuadros entre Antonio Jiménez y Mariana de la Rosa. La finalidad, según expresa el documento, era liquidar las deudas contraídas por préstamos en dinero líquido y arrendamiento del piso alto de una casa propiedad de la acreedora por la suma de 4.575 reales de vellón ${ }^{4}$.

Ambos documentos -la venta y el expediente judicial- trazan un retrato sociológico de los intervinientes en el contrato que permite encajar, al menos al vendedor, en el modelo del, poco transparente, mundo del coleccionismo y la venta de obras de arte de la España isabelina. Así, por el protocolo notarial, se sabe que Antonio Jiménez, el vendedor, era médico-cirujano, residente en Jerez y que, en 1852, vivía en arrendamiento en el piso superior de una casa propiedad de Mariana de la Rosa en la calle de las Arenas ${ }^{5}$. Con un alto grado de certeza sobre la identidad, se ha documentado, en 1820, la existencia en Jerez de un médico llamado Antonio Jiménez López, nacido en esa ciudad en 1802 y bautizado en la iglesia de San Miguel. Tras obtener el certificado de "vita et moribus" de limpieza de sangre y el aval de subsistencia del padre, es admitido en el Colegio de Medicina y Cirugía de Cádiz ${ }^{6}$. Con ciertas dudas, se le puede atribuir la posesión de algunas propiedades inmobiliarias en la calle Corredera y en el Llano de la Angustias, aunque, al día de hoy, son datos difíciles de contrastar ${ }^{7}$. En cualquier caso, su espacio vital giraba en torno al barrio de San Miguel en el que nació. Las calles Arenas, Corre-

\footnotetext{
3 En 1924, Pedro Gutiérrez de Quijano publicó la transcripción del expediente en el que se sigue la devolución de los cuadros GUTIERREZ DE QUIJANO Y LÓPEZ, Pedro. La Cartuja de Jerez, Jerez: Imprenta literaria jerezana, 1924, PP. 123-129. La actual referencia del expediente es ARCHIVO MUNICIPAL DE JEREZ DE LA FRONTERA (en adelante A.M.J.F.), leg.107, expdte. 3403, 1856. Citado por CABALLERO RAGEL, Jesús. Obras atribuidas a Zurbarán y su Escuela en Jerez de la Frontera, Revista de Historia de Jerez, n05, 1999, págs. 19-44. Disponible en https://www.revistadehistoriadejerez.com/ revista-de-historia-de-jerez/volumen-5-1999/

4 ARCHIVO HISTÓRICO PROVINCIAL DE CÁDIZ (en adelante A.H.P.C.). Protocolos de El Puerto de Santa María,leg. 1090, fol. 28-31v.

5 Ver expediente de la nota 3. Fol. $15 \mathrm{v}$.

6 ARCHIVO DE LA UNIVERSIDAD DE CÁDIZ (en adelante A.U.C.), C-10 RC, leg. 32, carpetilla 5, expediente 4. Expedientes de admisión y limpieza de sangre de alumnos del Colegio Nacional de Medicina y Cirugía. Agradezco a D. Francisco Herrera Rodríguez la sugerencia de localizar esta información.

7 En relación con asientos e inscripciones erróneas en el Registro de la Propiedad de Jerez, en 1868 aparece Antonio Jiménez como propietario de una casa en el "llano de las Angustias". España, Registro de la Propiedad de Jerez de la Frontera. [En línea] Gaceta de Madrid, 29 de septiembre de 1868, pág, 10. [Consulta:28/02/2021]. Disponible en https:// www.boe.es/datos/pdfs/BOE//1868/273/A00009-00012.pdf.

En un anuncio similar del mismo año, también figura un Antonio Jiménez como propietario de una casa en la calle Corredera. España, Registro de la Propiedad de Jerez de la Frontera. [En línea] Gaceta de Madrid, 24 de septiembre de 1868, pág, 13. [Consulta: 28/02/2021]. Disponible en https://www.boe.es/datos/pdfs/BOE//1868/268/A00010-00013.pdf
} 
dera, Llano de la Angustias, e incluso la calle de la Higuera (residencia de los padres) constituyen un entorno urbano muy concreto con el que puede asociarse al médico jerezano. Otros datos localizados permiten saber que ejerció su actividad profesional para el ayuntamiento jerezano, participando en 1855 en el control sanitario de los prostíbulos; que fue un médico de cierta relevancia en el contexto de la ciudad ${ }^{8}$ y que, años antes, en 1833, editó un texto sobre el cólera morbo ${ }^{9}$. De cualquier manera, y pese a las dudas biográficas expresadas, es factible hablar de un profesional en activo con cierto excedente económico, cuyo perfil se ajusta al modelo historiográfico de una burguesía de profesionales, que se incorporaba en el país al fenómeno del coleccionismo como sustituta de la aristocracia y de la iglesia ${ }^{10}$.

De Mariana de la Rosa, la parte compradora, sabemos que en 1825 vivía en la calle Évora de Jerez, una transversal a la calle Corredera y por tanto cercana al domicilio de Antonio Jiménez; que estaba casada con José de Arambillote, con quien tenía, al menos, una hija de la que era administradora legal de sus bienes por ausencia del padre ${ }^{11}$. La familia poseía en ese año una viña en el pago de Añina del término municipal jerezano y algunas propiedades inmobiliarias a nombre de uno y otro cónyuge ${ }^{12}$.

La venta de cuadros acordada entre ambos resulta de gran interés. La cercanía con el procedimiento judicial sobre los cuadros de la cartuja jerezana sugiere importantes conexiones

8 En octubre de 1855 el ayuntamiento de Jerez procedió a reglamentar la prostitución en la ciudad y para ello organizó el término en seis distritos sanitarios, uno de la cuales estaba dirigido por Antonio Jiménez. GUEREÑA, Jean Louis. La prostitución en la España Contemporánea, Madrid: Marcial Pons, 2003, pág. 191

Un doctor Jiménez aparece citado en un artículo publicado por Francisco Revuelta Carrilo y Montel en la Gaceta Médico-Quirúrgica Jerezana que hacía referencia a un caso clínico de 1868. Del mismo modo, el doctor Antonio Jiménez también aparece como asistente a la constitución en 1871 de la Junta de Jerez de la Frontera de la Asamblea Médico-Farmacéutica Española. Datos citados por HERRERA- RODRÍGUEZ, Francisco. Indización y estudio de la “Gaceta Médico-Quirúrgica Jerezana (1871-1872). Cultura de los Cuidados (Edición digital), 23 (54), 2019. Recuperado de http://dx.doi.org/10.14198/cuid.2019.54.11

9 JIMÉNEZ LOPEZ, Antonio. Desarrollo, causas, síntomas, pronóstico y tratamiento racional o fisiológico del Colera Morbo epidémico, escrito en lenguaje acomodado para la inteligencia del público por el doctor D. Antonio Jiménez y López. Jerez: Imprenta de José Bueno, 1833. [En línea] Consulta realizada el 27/02/2021. Disponible en http://bdh-rd.bne.es/viewer. vm?id=0000117249\&page $=1$

10 Francesc Fontbaona retrata al coleccionista burgués del siglo XIX como interesado en piezas antiguas y entre ella la pintura clásica, cuya finalidad era reflejar el prestigio de sus residencias, dejando relegado al arte del momento a funciones ornamentales. FONTBONA, Francesc. Comercio y difusión del arte en la España del siglo XIX. Modelos, intercambios y recepción artística (de las rutas marítimas a la navegación en red). Palma de Mallorca: Universitat de les Illes Balears, 2008, p. 547. Disponible en https://arteceha.eu/wp-content/uploads/Actas/actas-volumen-1.pdf

11 ARCHIVO MUNICIPAL DE JEREZ DE LA FRONTERA (en adelante A.M.J.F.), Escribanía de Antonio Diosdado, 1825, fol.21-21v. En el documento se solicita un préstamo reembolsable para la explotación de la viña. Mi agradecimiento a D. Pablo Pomar Rodil por la localización de este documento.

12 Al respecto en 1869 figuraba en el Registro de la Propiedad de Jerez una parte de casa en la calle Corredera a nombre de Mariana de la Rosa. España, Registro de la Propiedad de Jerez de la Frontera. [En línea] Gaceta de Madrid, 31 de enero de 1869, p. 3. [Consulta 28/02/2021]. Disponible en https://www.boe.es/datos/pdfs/BOE//1869/031/A0000300003.pdf

Del mismo modo, en 1868 una casa en la calle Alquiladores a nombre de José Arambillote. España, Registro de la Propiedad de Jerez de la Frontera. [En línea] Gaceta de Madrid, 31 de enero de 1868, p. 12. [Consulta 28/02/2021]. Disponible enhttps://www.boe.es/datos/pdfs/BOE//1868/344/A00009-00013.pdf 
entre los dos asuntos. Antonio Jiménez vende un total de 26 cuadros para pagar una deuda. Del literal del documento se deduce que era poseedor de una colección de pintura y objetos de valor más extensa, ya que las partes acuerdan que la acreedora "escogiese lo que le acomodase del menaje de su casa hasta cubrir aquella suma y por los precios convencionales que ambos le señalasen" y de ese menaje seleccionó " de las pinturas al óleo que tiene el compareciente" las que figuran en la relación que incorpora el protocolo (Tabla I) ${ }^{13}$. El documento de venta define pues parte de una colección de pinturas, a la vez que dibuja el perfil de un coleccionista de Jerez, así como pone de manifiesto procedimientos soterrados relacionados con el comercio artístico.

\section{2. ¿UN COLECCIONISTA?}

Antonio Jiménez se ajusta al modelo de comportamiento de ciertas categorías sociales en que coleccionismo, expolio y mercado de bienes artísticos iban de la mano, cuestión ésta que la bibliografía ha puesto de manifiesto de manera contundente. Al respecto, Martínez Plaza ha dado algunas pautas del coleccionismo burgués en el Madrid isabelino que, salvadas las diferencias, define el modelo de Antonio Jiménez. Así, menciona el incremento durante la etapa isabelina de una burguesía coleccionista formada por profesionales liberales que, a causa de la desamortización y el descontrol inicial en la custodia e inventario de los bienes artísticos, podía acceder sin grandes inversiones a bienes desamortizados. Este grupo se caracterizó por generar sus propias galerías de entre 50 y 300 pinturas para interiores domésticos y con una opción clara hacia la pintura antigua en detrimento de los artistas coetáneos. En este sentido y por tener puntos de referencia, en Madrid ha detectado la existencia de 91 coleccionistas ${ }^{14}$, mientras que en Sevilla Rafael Cómez habla de la existencia en 1842 de hasta siete colecciones con un número variable de cuadros ${ }^{15}$.

La finalidad de estas colecciones estaba relacionada con el interés artístico de sus promotores, la decoración de los interiores domésticos y el prestigio social que otorgaban; sin embargo, no podemos dejar a un lado la función económica. En ocasiones eran utilizadas como objetos financieros para cubrir garantías de préstamos, e incluso como pago de deudas con-

13 Véase nota 4.

14 Al respecto véase MARTínEZ PLAZA, Pedro J. El coleccionismo de pintura en Madrid durante el siglo XIX. La escuela española en las colecciones privadas y el mercado, Madrid: Centro de Estudios Europa Hispánica, 2018, pp.109 y ss.

15 CómEZ RAMOS, Rafael. Coleccionista de pintura en Sevilla en 1842. Laboratorio de Arte, 5, T.II, 1993, PP. 159-165. Disponible en http://dx.doi.org/10.12795/LA.1992.105.28 
traídas $^{16}$. Pérez Mulet ha documentado el uso que en 1878 hace Diego Ruiz Blasco de su colección como garantía de un préstamo de 4.000 pesetas, aunque manteniéndola en usufructo ${ }^{17}$.

Sin embargo, el caso que nos ocupa presenta ciertas peculiaridades que comparadas con otros casos levanta sospechas sobre la finalidad de la transacción. Jiménez vendió parte de su colección a Mariana de la Rosa que por "no tener en su casa sitio donde colocar dichas pinturas suplicaba a Don Antonio Jimenez las dejase en su casa en el sitio en que se hallan, hasta que se removiesen dichos obstáculos o le acomodase salir de ellas" ${ }^{18}$. El acuerdo incluía una cláusula sobre el derecho de tanteo y retracto que apunta hacia un previsible retorno nada gravoso de la propiedad. Nótese, además que un año después, en 1852, se interpuso la denuncia por el robo de once cuadros de la Cartuja de Jerez que figuraban entre los vendidos a de la Rosa.

El hecho de que la venta se firmara en la cercana ciudad de El Puerto de Santa María y no en Jerez donde residían las partes; el hecho de que un notario y un abogado de Jerez estuvieran incluidos en la posterior denuncia; el hecho de que la valoración económica se hiciera sin un tasador de pintura y de mutuo acuerdo entre las partes, acordando unos precios que, como veremos, podrían ponerse en entredicho; el hecho de realizarse una anómala venta que permitía seguir disponiendo del bien y con cláusulas de retorno muy cómodas para el vendedor; el hecho de que no se ejecutase, caso de optar por la continuidad en el disfrute de los bienes, una garantía de préstamos, al modo del citado Ruiz Blasco, y el hecho, al fin, de la más que probable relación de amistad entre las partes evidencian intenciones ocultas, más relacionadas con una transferencia temporal de propiedad que con una venta. Una transferencia de propiedad que se acercaría más a un alzamiento u ocultamiento de bienes formalizado para entorpecer previsibles consecuencias ${ }^{19}$.

16 MARTÍnEZ PLAZA, Pedro J... op. cit. p. 178

17 Según Pérez Mulet Diego Ruiz fue secretario del XII Duque de Osuna, parece que buen pintor copista y tío de Pablo Ruiz Picasso. PÉREZ MULET, Fernando. Cádiz en el siglo XIX. Un episodio de pérdida patrimonial, en La dispersión de objetos de arte fuera de España en los siglos XIX $\gamma$ XX. Fernando Pérez Mulet, Immaculada Socias Batet (eds.), Publicacions i Edicions de la Universitat de Barcelona y Servicio de Publicaciones de la Universidad de Cádiz: Barcelona, pág. 275276.

Pero, además Ruiz Blasco debió extender su afición a piezas arqueológicas, así se deduce de la donación que realizó al Museo Arqueológico Nacional. En 1868, desde la Gaceta de Madrid, la Reina le agradece la donación de "varios importantes objetos" al Museo Arqueológico Nacional. Gaceta de Madrid, no 115 de 24 de abril de 1868. [En línea]. Disponible en https://www.boe.es/datos/pdfs/BOE//1868/115/A00001-00001.pdf. [Consulta 28/02/2021]

18 Véase nota 4

19 Téngase en cuenta que un año después se pone de manifiesto un complejo entramado de cesiones y propiedades de los lienzos que se suman a esta situación descrita. Sin entrar en valoraciones jurídicas y tan sólo a modo de marco referencial, el Código Penal de 1848 recogía en su artículo 432 la figura del alzamiento de bienes y en el 437 "la ocultación o enagenación maliciosa" para los no comerciantes, así como los de "estafa y otros engaños". Gaceta de Madrid, $n^{\circ}$ 4943, de 27 de abril de 1848. [En línea]. Disponible en https://www.boe.es/datos/pdfs/BOE//1848/4943/ A00002-00003.pdf. [Consulta 14/03/2021] 
Esta situación nos permite delimitar algo más el perfil coleccionista del médico jerezano. De ser valorados como simples mercancías, los cuadros se habrían vendido sin mayor consideración -la bibliografía citada refiere la existencia de numerosos intermediarios, comerciantes, mercaderes, marchantes que iban a la búsqueda de objetos artísticos con fines comerciales y de exportación ${ }^{20}$-. Sin embargo, el breve, pero ilustrativo documento notarial, describe entre líneas la necesidad del deudor de mantener unida su colección; de seguir en uso y disfrute de la misma en los muros de su residencia y de asegurarse el reintegro de su propiedad. El documento también da a entender la existencia de un "menaje en la casa" que se ofrecía a la acreedora para su selección por lo que cabe suponer que dispondría de otros objetos de interés para ser seleccionados. Del mismo modo, nos suministra información valiosa sobre al menos una parte de su colección que, como ya mencionamos, puede entenderse compuesta por un mayor número de cuadros y objetos que los 26 relacionados en el protocolo (Tabla I).

De esta sucinta relación incorporada al protocolo notarial podemos seguir deduciendo el perfil de coleccionista. Como era habitual en el modelo sociológico, hay mayoría de pintura religiosa que era la preferida por el coleccionista burgués; si bien con alguna excepción como los seis "países" ${ }^{21}$, un pasaje de la historia de Roma, un ciego tocando la guitarra y lo que el inventario cita como "una bieja". Tal vez estos cuadros podrían vincularse por su temática con producción contemporánea de filiación goyesca o costumbrista que como, afirma Martínez Plaza, fue una de las preferidas entre coleccionistas de una burguesía modesta $^{22}$. Punto igualmente relevante es la preferencia por determinados pintores y escuelas. Insistiendo en que los inventarios de los protocolos notariales suelen ser, por lo general, muy poco descriptivos $^{23}$, en esta ocasión se dispone de información complementaria que permite identificar a una parte de los artistas que formaban la colección. La denuncia cursada en 1852 especificaba que habían sido sustraídos dos zurbaranes, tres murillos, un alonso cano, un herrera (el Viejo), un valdés leal, un españoleto, y lo que la relación denomina un urbino, en alusión a Rafael Sanzio y a su Virgen de la Perla. Indudablemente son atribuciones no contrastadas, pero que apuntan a un tipo determinado de pintura, especialmente valorada en ese momento y que generó un mercado de copias e incluso falsificaciones de firmas ${ }^{24}$.

\footnotetext{
20 Ver nota 1

21 En el siglo XIX aún se utiliza el término "país" para denominar a los paisajes en pintura. Al respecto véase MADERUELO, Javier. El paisaje. Génesis de un concepto, Madrid: Abada Editores, 2005, p.30-31

22 MARTÍNEZ PLAZA, Pedro J. op.cit, p. 130

23 Es uno de los problemas a la hora de poder identificar las piezas. Guadalupe Carrasco ya hace mención al problema de especulación que genera la imprecisión de los catálogos de exposiciones de venta y de documentos notariales cuando analiza la colección de Richard W. Meade. CARRASCO GONZÁLEZ, Guadalupe. La colección de pintura reunida.... op.cit.

24 MARTÍnEZ PLAZA, Pedro J. op.cit, p. 111
} 
Tabla I

Relación de cuadros vendidos por Antonio Jiménez a Mariana de la Rosa en 1851

\begin{tabular}{|c|c|}
\hline Denominación del cuadro & Valoración \\
\hline Un San Pedro de tamaño natural con marco de madera amarillo & 400 reales de vellón \\
\hline Jesucristo acabado de crucificar, con marco ídem & 400 reales de vellón \\
\hline La Sacra Familia, marco ídem & 80 reales de vellón \\
\hline Santa Rosa, marco ídem & 98 reales de vellón \\
\hline San Franciso de Asis, ídem ídem & 100 reales de vellón \\
\hline San José de medio cuerpo, ídem & 20 reales de vellón \\
\hline La Virgen de Belén, ídem & 20 reales de vellón \\
\hline Santa María Egipciaca, ídem & 160 reales de vellón \\
\hline San Bruno tamaño natural, ídem & 1.000 reales de vellón \\
\hline Una Adoración de Reyes & 120 reales de vellón \\
\hline Otra ídem mas chiquita & 20 reales de vellón \\
\hline Otra de Reyes chiquita & 20 reales de vellón \\
\hline Visita de santa Isavel (sic) & 40 reales de vellón \\
\hline La cabeza de San Gerónimo & 100 reales de vellón \\
\hline Seis países & 60 reales de vellón \\
\hline La sombra de Samuel, la pitonisa y un rey, en cuadro apaisado & 90 reales de vellón \\
\hline Un pasaje de la historia de Roma & 90 reales de vellón \\
\hline Un santo bautizando a un hereje & 64 reales de vellón \\
\hline San Ildefonso recibiendo una casulla de la Sma. Virgen & 72 reales de vellón \\
\hline Una Virgen de Belén pequeñita & 10 reales de vellón \\
\hline Un ciego tocando la guitarra & 6 reales de vellón \\
\hline Una bieja (sic) & 8 reales de vellón \\
\hline Un cuadro representando el labatorio (sic) del niño Jesús & 40 reales de vellón \\
\hline Una Virgen de Belén o de la Perla en tabla con marco dorado & 1.000 reales de vellón \\
\hline Un Juan Bautista también con marco dorado & 120 reales de vellón \\
\hline
\end{tabular}


La valoración económica de la colección es también un punto importante del perfil coleccionista. Como ya destacamos, la venta muestra algunas incoherencias con la lógica de una transacción mercantil ${ }^{25}$. Partiendo de que la parte compradora no estaba especialmente interesada en la posesión de los cuadros, la auto-tasación de las pinturas realizada por acuerdo de las partes es un ejemplo de esa anomalía. En este sentido los precios acordados no reflejan la realidad del mercado artístico del momento. Partiendo de la base de que algunos de los cuadros correspondían con "obra antigua", la horquilla de precios es muy amplia estableciéndose grandes diferencias en la escala de valores aplicada. Así, los más elevados se estipularon en 1.000 reales de vellón, mientras que el segundo valor en la escala se redujo a 400 reales, quedando más bajos los que podrían ser considerados como modernos, reduciéndose algunos a 10 reales de vellón. Habida cuenta de que los de mayor valor fueron denunciados como robo de la Cartuja y atribuidos a Zurbarán y a Rafael de Urbino no parecen valoraciones muy adecuadas o muy en consonancia con otras tasaciones ${ }^{26}$.

No se tiene, de momento, más información sobre la figura de Antonio Jiménez. Queda abierta la puerta a localizar el testamento y en su caso algún documento que acreditase el reintegro de la colección por cuanto, como decimos, un año después algunos delos cuadros vendidos son inventariados nuevamente como bienes de su propiedad. El perfil, en suma, de un diletante que debió dedicar parte de sus rentas personales a la adquisición más o menos legal de objetos artísticos y que siguiendo los vaivenes del momento, aprovechó la escasa valoración de la pintura para hacerse con obras de cierta relevancia.

\section{3. ¿EXPOLIADOR?}

El proceso histórico que vivió el monasterio cartujo de Na. Sra. de la Defensión de Jerez durante el siglo XIX fue muy problemático tanto para la conservación del inmueble como para los bienes muebles que contenía. A través de sus investigaciones, el profesor Cirici Narváez ha desgranado el complejo itinerario de los procesos desamortizadores, con especial referencia a los acontecimientos generados a partir de 1835. De ese tiempo histórico convulso

25 Al respecto resulta especialmente interesante la reflexión que Carlos Reyero realiza sobre lo "cándido" que supone el ignorar que las obras artísticas están sometidas al mercado del mismo modo que otros bienes. REYERO, Carlos. El valor del precio. Tasación y compraventa de pinturas en el Madrid Isabelino (1850-1868). e-artDocuments: revista sobre col-leccions i col-leccioniste. [en línea]. 2009, 1, Seminari: Comerç, Exportació, Falsificació d'objectes d'art. [Consulta 01/03/2021]. ISSN e 2013-6277. Disponible en htps://www.raco.cat/index.php/e-art/article/view/189042/254270

26 Por disponer de un punto de referencia en el entorno geográfico y siempre partiendo de la base de que son atribuciones, en una partición de bienes realizada en 1850 en la ciudad de El Puerto de Santa María, lugar donde recordemos se protocoliza la venta, se valoraron tres cobres, que el documento cita de Rubens, en 12.000 reales de vellón. A.H.P.C. Protocolos de El Puerto de Santa María, leg. 1079, fol. 252 v.

Tómese también en consideración, aunque desde un punto de vista geográfico y social diferente, las tablas de valoración publicadas en REYERO, Carlos. El valor del precio... op.cit. 
surgieron ventas legales, así como robos de objetos artísticos de los conventos suprimidos en general y de la cartuja jerezana en particular. Sin embargo, esos momentos también supusieron el inicio de la concienciación sobre la importancia de los bienes artísticos nacionales, así como de la incorporación de débiles aunque progresivas medidas de protección que se fueron desarrollando ante las quejas y denuncias de instituciones y figuras públicas ${ }^{27}$.

En este contexto se encuadra la otra cara de Antonio Jiménez. Además del coleccionista amante del arte, sus acciones delatan el uso de procedimientos ilegales en la obtención de piezas en un tiempo de expolios, robos y desaparición de objetos artísticos, esencialmente bienes muebles. Como el propio Cirici Narváez afirma, en 1835 se encargó a Antonio Mesa la elaboración del inventario de los bienes de La Cartuja. Mesa entregó al año siguiente un primer listado compuesto por 92 cuadros y 16 esculturas en el que ya se observaron irregularidades. Refiere también Cirici el abandono al que estaban sometidos los objetos artísticos, además de señalar la venta en 1838 de los seis famosos zurbaranes que acabaron repartidos entre Grenoble, Poznan y Nueva York ${ }^{28}$. Destaca Cirici la creación en 1843 de la una comisión de la Academia de Bellas Artes de Cádiz para la formación del museo provincial que se organiza en 1849 y se inaugura en 1852, años todos muy relevantes para todo el proceso que estamos poniendo de relieve ${ }^{29}$. El caso es que la cartuja jerezana, pese a su declaración como Monumento Nacional, fue muy vulnerable en todo momento, de hecho, avanzado el siglo se seguía denunciando la desaparición de objetos de valor del inmueble ${ }^{30}$.

La venta de los 26 cuadros en 1851 y la denuncia cursada por José María Navarro y Osorio ${ }^{31}$ en junio de 1852 ante el Gobernador de la provincia, relaciona a Antonio Jiménez con la participación

27 Al respecto remitimos a los fundamentales CIRICI NARVÁEZ, Juan Ramón. El "Informe de La Vega". Situación y estado de la Cartuja de Jerez en el año 1856. Revista de Historia de Jerez, 2, 1996, Pp. 7-24.

CIRICI NARVÁEZ, Juan Ramón. Inventarios, pleitos y otras incidencias de bienes y obras artísticas desamortizadas en la provincia de Cádiz. Colecciones, expolio, museos y mercado artístico en España en los siglos XVIII y XIX (María Dolores Antigüedad del Castillo Olivares dir. Amaya Alzaga Ruiz coord.). Madrid: Editorial Universitaria Ramón Areces, 2011

28 Al respecto véase también PEMAN Y PEMARTíN, César. Catálogo del Museo Provincial de Bellas Artes de Cádiz(Pinturas). Madrid: Langa y Cía, 1964, PP. VI-VII

29 Ibídem

30 Por ejemplo, en 1888 Francisco de Asís Vera y Chelier en la carta de agradecimiento a Fidel Fita por su nombramiento como director del museo arqueológico de Cádiz, denuncia el estado del edificio "a punto de desplomarse" y dice haber realizado un inventario de lo existente a la fecha por cuanto se había detectado el intento de robo de seis rejas. ARCHIVO HISTÓRICO DE LA COMPAÑÍA DE JESUS (sede Alcalá de Henares). Carta de Francisco Asís Vera a Fidel Fita agradeciendo su nombramiento y denunciando el expolio al que se halla sometida la Cartuja de Jerez cuyo estado es ruinoso. En línea. (Disponible en http:/www.cervantesvirtual.com/nd/ark:/59851/bmc2r587]. [Consulta 06/03/2021]. Citado por ORELLANA GONZÁLEZ, Cristóbal. Documentación histórica sobre la Cartuja de Santa María de la Defensión en el Archivo Municipal de Jerez y otros archivos. Revista de Historia de Jerez, 23, 2020, Pp. 85-128

31 José María Navarro y Osorio declaraba en la denuncia que vivía en Sevilla en la Plaza del Duque y en casa de la Marquesa Viuda del Real Tesoro. Véase Nota 2, fol. 36.

En un anuncio publicado en El Heraldo de Madrid el 18 de mayo de 1848 figuraba como intermediario en la venta de una hacienda de olivar. En el anuncio especifica que vivía en la calle de los Tiros (actual Martínez Montañés), 28 de Sevilla que corresponde con el domicilio especificado en la denuncia de la Plaza del Duque. Se desconoce el vínculo con este proceso, sin embargo, resulta esclarecedor o al menos sospechoso que el denunciante fuera un comisionista, si bien es cierto que, al parecer, vinculado con el marquesado del Real Tesoro.

El Heraldo de Madrid, $\mathrm{n}^{\circ} 1830$ de 18 de mayo de 1848, p.3. [En línea]. Disponible en http://hemerotecadigital.bne.es/issue. vm?id=0003405555\&page=4\&search=\%22Jos\%C3\%A9+Mar\%C3\%ADa+Navarro+y+Osorio\%22\&lang=es. [Consulta 06/03/2021]. 
en los robos/expolio de los bienes del monasterio. En este contexto, la denuncia obligó al Ministerio de la Gobernación a la apertura de diligencias judiciales para la recuperación delos cuadros ${ }^{32}$.

Del procedimiento judicial ${ }^{33}$, resulta de especial interés las diligencias practicadas en los domicilios de los denunciados para la localización e inmovilizado de los lienzos. La documentación refleja los cambios de ubicación de los cuadros que realizaron los implicados, resultando bastante significativo que tan sólo a Antonio Jiménez se le retiraran los cuadros de su domicilio ${ }^{34}$. Este comportamiento de los agentes judiciales aumenta las sospechas de ocultación realizada con la venta de 1851. Pese a las dificultades para identificar al día de hoy los cuadros y como puede observarse en la Tabla II, todos los que figuraban en la denuncia estaban en poder de Antonio Jiménez en 1851. Pero, además, el procedimiento judicial destapa la presencia de otros implicados en este robo. Ya Navarro en su denuncia indicaba que el poseedor de los once cuadros expoliados era Antonio Jiménez, pero que parte de los cuadros, debido a "cierta negociación" estarían en manos de Francisco Pérez Gómez, escribano público de Jerez, residente en la calle Corredera y con escribanía en la calle Plateros o, en su caso, en el domicilio de José Pedro y Jiménez, abogado de la ciudad ${ }^{35}$.

En este sentido es interesante señalar cómo en las diligencias judiciales de inspección de las residencias de los denunciados se incluye, sin haber sido nombrado en la denuncia, a Julián Pemartín, obviándose, en cambio, la inspección del domicilio del notario. Todo ello nos dibuja un complejo entramado y una red de personajes vinculados con esa burguesía profesional y empresarial que alimentaron sus colecciones personales a través de estos medios y a los que tan sólo se ponía coto en circunstancias especiales ${ }^{36}$.

32 En la Gaceta de Madrid se publicó la siguiente notificación: “Ministerio de la Gobernación. Sección de ramos especiales.- Negociado $2^{\circ}$. El Gobernador de la provincia de Cádiz, con fecha 3 del actual, participa a este Ministerio el descubrimiento de 11 cuadros de gran valor, originales de los afamados pintores Murillo, Zurbaran, Herrera, Cano, Valdés, el Españoleto y Urbina (sic), que había sido robados hace muchos años del monasterio de la Cartuja de Sevilla (sic)". Gaceta de Madrid, $n^{\circ} 6603$ de 21 de julio de 1852. [En línea]. Disponible en https://www.boe.es/datos/ pdfs/BOE//1852/6603/A00001-00001.pdf. [Consulta 28/02/2021].

33 Véase nota 3.

34 Los cuadros de la denuncia en poder de Antonio Jiménez se entregaron en depósito a Juan Lomón, mientras que el resto de los inspeccionados los mantuvieron en su domicilio. Véase nota 3, fol. 14-20v.

Con respecto al depositario, pudiera ser también un médico de la ciudad de Jerez que aparece citado en HERRERA RODRÍGUEZ, Francisco. op. cit., p.103.

35 Existió un José Pedroy Jiménez vinculado al mundo dela judicatura que ocupó distintos puestos en los juzgados de Lebrija,Écija y en concreto en el juzgado de Santa Cruz de Cádiz en 1855, jubilándose en 1885 como fiscal dela Audiencia de Las Palmas. Véase al respecto: La Época, 27 de julio de 1855. En línea. Disponible en http://hemerotecadigital. bne.es $/$ issue.vm?id=0000071659\&page $=1 \&$ search $=\% 22 \mathrm{Jos} \% \mathrm{C} 3 \% \mathrm{~A} 9+\mathrm{P} \% \mathrm{C} 3 \% \mathrm{~A} 9 \mathrm{rez}+\mathrm{Jim} \% \mathrm{C} 3 \% \mathrm{~A} 9 \mathrm{nez} \% 22 \& \mathrm{lang}=\mathrm{es}$, [Consulta 07/03/2021]

También, Gaceta de Madrid, 10 de septiembre de 1885, [En línea]. Disponible en https:/www.boe.es/datos/pdfs/ BOE//1885/253/A00801-00802.pdf. [Consulta 07/03/2021]

36 Sobre colecciones y coleccionistas en Jerez véase CABALLERO RAGEL, Jesús. El coleccionismo jerezano durante el siglo XIX y principios del XX. El Museo de Santo Domingo. Revista de Historia de Jerez. 11-12, 2005-06, Pp. 305-333 


\section{Tabla II}

\section{Cuadro comparativo de los inventarios}

\begin{tabular}{|c|c|c|c|c|}
\hline $\begin{array}{c}\text { ANTONIO JIMENEZ. } \\
\text { Venta de cuadros a } \\
\text { Mariana de la Rosa. } \\
\text { 10/02/1851 }\end{array}$ & $\begin{array}{l}\text { JOSÉ MARÍA NAVARRO } \\
\text { OSORIO. Denuncia. } \\
\text { 27/06/1852 }\end{array}$ & $\begin{array}{l}\text { ANTONIO } \\
\text { JIMÉNEZ. } \\
\text { Diligencia } \\
\text { judicial. } \\
\text { 01/07/1852 }\end{array}$ & $\begin{array}{c}\text { JOSÉ PÉREZ } \\
\text { JIMÉNEZ. } \\
\text { Diligencia } \\
\text { judicial. } \\
\text { 01/07/1852 }\end{array}$ & $\begin{array}{c}\text { JULIÁN } \\
\text { PEMARTÍN. } \\
\text { Diligencia } \\
\text { judicial. } \\
\text { 01/07/1852 }\end{array}$ \\
\hline $\begin{array}{l}\text { Un San Pedro del tamaño } \\
\text { natural con marco de madera } \\
\text { amarillo }\end{array}$ & San Pedro de Herrera & & $0,83 \times 0,62 \mathrm{~m}$ & $\begin{array}{c}1.94 \times 0.879 \\
\mathrm{~m} .\end{array}$ \\
\hline $\begin{array}{l}\text { Jesucristo acabado de } \\
\text { crucificar, marco ídem }\end{array}$ & $\begin{array}{l}\text { Jesucristo en el acto } \\
\text { de expirar de Cano }\end{array}$ & & 3.75 x $1.25 \mathrm{~m}$ & $\begin{array}{l}1.94 \times 1.38 \\
\mathrm{~m} .\end{array}$ \\
\hline La Sacra familia, marco ídem & Sacra Familia murillo & $1.50 \times 1,22 \mathrm{~m}$. & & \\
\hline Santa Rosa, marco ídem & Santa Rosa de Valdés & $1.71 \times 1.01 \mathrm{~m}$. & & \\
\hline San Francisco de Asís, ídem & $\begin{array}{c}\text { San Francisco Asís de } \\
\text { Zurbarán }\end{array}$ & $1.11 \times 1 \mathrm{~m}$ & & \\
\hline Santa María Egipciaca, ídem & $\begin{array}{l}\text { Sta. María Egipciaca } \\
\text { de Murillo }\end{array}$ & & & $\begin{array}{c}1.11 \times 1.042 \\
\mathrm{~m}\end{array}$ \\
\hline $\begin{array}{c}\text { San Bruno tamaño natural, } \\
\text { ídem }\end{array}$ & $\begin{array}{l}\text { San Bruno de } \\
\text { Zurbarán }\end{array}$ & & & $\begin{array}{l}0.973 \mathrm{x} \\
1.252 \mathrm{~m}\end{array}$ \\
\hline Visita de Santa Isabel & $\begin{array}{l}\text { Santa Isabel de } \\
\text { Murillo }\end{array}$ & $\begin{array}{l}0.950 \times 0.950 \\
\mathrm{~m}\end{array}$ & & \\
\hline La cabeza de San Jerónimo, & $\begin{array}{l}\text { Cabeza de San } \\
\text { Jerónimo Españoleto }\end{array}$ & & & $\begin{array}{l}0.563 \mathrm{x} \\
0,483 \mathrm{~m}\end{array}$ \\
\hline $\begin{array}{l}\text { San Ildefonso recibiendo una } \\
\text { casulla de la Virgen }\end{array}$ & $\begin{array}{l}\text { San Ildefonso de } \\
\text { Valdés }\end{array}$ & $\begin{array}{c}0.835 \times 0.532 \\
\mathrm{~m}\end{array}$ & & \\
\hline \multirow[t]{3}{*}{$\begin{array}{l}\text { Una Virgen de Belén o de La } \\
\text { Perla, en tabla con marco } \\
\text { dorado }\end{array}$} & $\begin{array}{l}\text { Tabla La Perla de } \\
\text { Urbino. }\end{array}$ & $\begin{array}{c}1.043 \times 0.950 \\
\mathrm{~m}\end{array}$ & & \\
\hline & & & $\begin{array}{c}\text { Sagrada } \\
\text { familia. } \\
1.25 \times 0.835 \mathrm{~m} .\end{array}$ & \\
\hline & & & $\begin{array}{l}\text { Sacra familia. } \\
0.835 \times 0.626 \mathrm{~m}\end{array}$ & \\
\hline
\end{tabular}


El caso es que de los once cuadros denunciados, Antonio Jiménez había vendido un año antes a Mariana de la Rosa otros tantos con el mismo título o motivo iconográfico ${ }^{37}$. En la Tabla II se puede observar la esclarecedora comparación sobre la propiedad de los once lienzos, quedando patente también la existencia de otros trece en manos del médico jerezano (Tabla I) que en ningún momento se toman en consideración y que por los títulos y temática no resultaría extraño que tuvieran un origen parecido. En este sentido sería fundamental poder ahondar en el proceso de construcción de la colección. Cuando se realiza la diligencia judicial en el domicilio de Jiménez en la calle Arenas en ningún momento se citan otras obras, si bien se mencionan indirectamente al referirse a la sala principal de la casa como "adornada entre otras cosas por varios cuadros de pintura al óleo entre los cuales, examinados que fueron por dicho Señor en presencia de D. Antonio Jiménez, se hallaron las que la designación que este mismo fue haciendo de ellas", así como alguno más en el "gabinete alcoba".

En la misma Tabla II se puede observar que el abogado José Pérez y Jiménez tenía en la sala y alcoba de su domicilio cuatro lienzos del mismo tema que los denunciados y que Julián Pemartin, hasta cinco que él declaraba como adquiridos legalmente a Fray Bartolomé Pinto. De las tres diligencias de inspección realizadas se inmovilizaron quince cuadros y no fue hasta 1856 en que, finalizado el procedimiento judicial, se dictaminó la entrega de los once cuadros a la Comisión de la Academia Provincial de Bellas Artes ${ }^{38}$.

\section{A MODO DE CONCLUSIONES}

Pese a que quedan cabos sueltos en este proceso cuyo conocimiento alumbraría aún más este asunto de ámbito local, aunque incluido dentro del más extenso y complejo proceso histórico de los bienes artísticos desamortizados; lo cierto es que la información obtenida permite vislumbrar algunas cuestiones relevantes del mercado artístico. El conocimiento de la figura de Antonio Jiménez, cuyo complementario perfil de coleccionista y expoliador permite incluirlo en los modelos burgueses de la etapa isabelina, sigue ofreciendo infor-

\footnotetext{
37 Resulta difícil en base a las relaciones o inventarios de protocolos notariales o judiciales sin peritajes, determinar la identidad de los cuadros a través del título dado. Sin embargo, dada la proximidad de los hechos no parece improbable que sean los mismos

38 La discrepancia en el número de cuadros inmovilizados en las diligencias judiciales y los entregadas a la Academia de Bellas Artes, queda aclarada por los cuatro lienzos en poder de José Pérez y Jiménez. Como puede observarse en la Tabla II, las imágenes de un Crucificado se repiten en los inventarios de Julián Pemartín y José Pérez y Jiménez, del mismo modo las dos pinturas de la Sagrada Familia. En el proceso judicial figura un escrito de José Pérez dirigido al juez rogándole que subsanara la confusión de incluir sus cuatro cuadros en el listado de piezas denunciadas, entre otras cosas porque los inventariados en los domicilios de Antonio Jiménez y Julián Pemartín completaban la relación de los once cuadros. Véase nota 3
} 
mación sobre los soterrados movimientos de piezas desamortizadas en el interior del país y ya no con la exclusiva intención de exportarlos. Un capítulo del mercado artístico decimonónico que, por su propia ilegalidad, requería de estas maneras ocultas y que por tanto no constan de manera habitual en fuentes documentales visibles, pero cuyo seguimiento, como es el caso de la venta que se estudia en este artículo, podría esclarecer la procedencia y actual propiedad de muchos bienes del actual patrimonio histórico-artístico del país ${ }^{39}$.

Por otra parte, la consideración de los objetos artísticos como mercancía valiosa los convertía en materia de transacciones comerciales -legales e ilegales-. Esto, en principio considerado negativo, también llevaba implícito una revalorización, no sólo económica, de la pintura por parte de esta burguesía coleccionista del país. Su paulatina puesta en valor a nivel de coleccionismo privado, pero también como integrante de los bienes del país, fue contribuyendo desde un punto de vista positivo a que, como se demuestra en el texto, desde los poderes públicos, se fuera generando infraestructuras y aparato legal para la consolidación de los bienes artísticos de la nación. Al respecto resulta interesante la justificación que se utiliza en la denuncia de 1852: “he creído oportuno ponerlo en conocimiento de V.E. porque debiendo pertenecer dichos objetos a la Nacion y con mayor razón por el mucho valor que se les considera, se sirva tomar las disposiciones que estime oportunas para su adquisición”40.

39 En principio no se sabe más de los once cuadros que tras ser entregados a la Academia de Bellas Artes de Cádiz iban a formar parte de los fondos del museo provincial de la ciudad. Consultado el catálogo publicado por César Pemán en 1964 (Véase PEMÁN PEMARTÍN, César. op.cit.) aparecen algunas coincidencias en cuanto al motivo iconográfico, pero que no guardan correspondencia con las medidas suministradas por la documentación que se cita en el texto. Es el caso, entre otros, de varios cuadros de San Pedro, de la Virgen de Belén, de San Bruno o de San Juan Bautista.

40 Ver nota 2 , fol. 31-31v 